\title{
Quantitative and Qualitative Losses in Paddy, Maize and Greengram Stored under Household Conditions in Anuradhapura District of Sri Lanka
}

\author{
J.M.P. Kumari ${ }^{1}$, L.K.W. Wijayaratne ${ }^{2 *}$, N.W.I.A. Jayawardena ${ }^{1}$ and W.C.P. Egodawatta ${ }^{2}$
}

${ }^{1}$ Department of Animal and Food Sciences, Faculty of Agriculture, Rajarata University of Sri Lanka, Anuradhapura (50000), Sri

Lanka.

${ }^{2}$ Department of Plant Sciences, Faculty of Agriculture, Rajarata University of Sri Lanka, Anuradhapura (50000), Sri Lanka.

\section{Correspondence:} wollylk@yahoo.com ORCID: 0000-0003-3748-040X

\section{Funding Acknowledgement:} Rajarata University of Sri Lanka (Grant No.

RJT/RP\&HDC/2015/Agri/R/09).

\begin{abstract}
Substantial losses are common due to various reasons of durable crops during storage, which threatens economy, health and food security. Despite the frequent reports on post-harvest losses of paddy and other cereals throughout Sri Lanka, a comprehensive study has not been conducted in Anuradhapura district in recent past to assess storage losses of aforesaid commodities. Objectives of this study were to find out main types of durable crops stored following harvest, and their quantitative and qualitative losses incurred during storage period at the household level in Anuradhapura district of Sri Lanka. Data were collected throughout Anuradhapura district representing all 22 divisional secretariats. The main stored commodities were paddy, maize and greengram. The storage period varied from 4 to 12 months. The storage losses of $\mathrm{Nadu}$ and Samba rice varietal types respectively were highest in Palagala and Kekirawa, whereas losses were minimum in Rambewa and Galenbindunuwewa. The main qualitative losses were the presence of damaged seeds, grain flour/dust, grains without kernel and faecal matter. The study highlights that severe quantitative and qualitative losses occur during storage of rice, maize and greengram, and appropriate remedial measures are needed to be developed to minimize the said losses ensuring food security.
\end{abstract}

Keywords: Anuradhapura district, cereals, storage loss, qualitative, quantitative 


\section{Introduction}

As the production of cereals is seasonal, the excessive production needs to be stored to meet the demand during off-season (Proctor 1994; Dowell and Dowell 2017). Numerous types of quantitative and qualitative deterioration of a food crop occur from harvest/production until consumption. Those damage reduce the nutrient content, caloric value, edibility, and consumer acceptability of food (Kader 2002; Hagstrum and Subramanyam 2006). The various losses occurred during storage of food eventually cause low marketability and escalates the prices of food (Zorya et al. 2011). Estimates by the Food and Agriculture Organization of U.N. indicate the global loss of about 1.3 billion tonnes of food annually (Gustavson et al. 2011). In developing countries, the losses of stored food products can be high as $50 \%$ of total production (Wijayaratne et al. 2018). In Sri Lanka, approximately LKR 1820 billion is lost annually due to post-harvest losses of rice and other durable crops (Wijayaratne 2020). Significant losses occur in the unmilled rice, other cereals and pulses during operations such as harvesting, threshing, winnowing, bagging, transportation, storage and processing before reaching to consumers. In Sri Lanka, the post-harvest losses of paddy reach approximately 15\%, which also include a storage loss of $4-6 \%$ (Palipane 2000; Wijayaratne et al. 2009). Anuradhapura district is a major growing area for rice and other grains in Sri Lanka. Even though, substantial losses of food are frequently reported (Wijayaratne and Rajapakse 2015), no recent update is available with respective to the stored-product losses of durable agricultural commodities in
Anuradhapura district. Hence, the objectives of this study were to identify the types of major durable crops stored, proportion of storage, and the types of losses occurred during storage in Anuradhapura district of Sri Lanka.

\section{Materials and Methods}

\section{Data Collection}

The data were collected by a survey conducted throughout the Anuradhapura district representing all 22 divisional secretariats: Rambewa, Medawachchiya, Mihintale, Kahatagasdigiliya, Thirappane, Kekirawa, Nachchaduwa, Thambuththegama, Galnaewa, Thalawa, Nuwaragampalatha-Central, Nuwaragampalatha-East, Rajanganaya, Nochchiyagama, Galenbindunuwewa, Palugaswewa, Palagala, Ipalogama, Horowpothana, Padaviya, Vilachchiya, Kebithigollawa. From one divisional secretariat, twenty (20) farmer families were selected. In total, 440 farmer families were used to collect the data. These farmer families were physically met and interviewed to gather the required information. A structured questionnaire was designed to collect the information to meet the objectives. Accordingly, the types of crops grown, yield obtained from each crop, amount of crop stored, amount lost during storage, different types of damage observed during storage and its quantity were collected. The data were collected during 2015/2016 Maha season.

\section{Statistical analyses}

Data collected from each DS division with respective of amount of each crop harvested, amount stored, types of losses experienced, quantity of each loss during storage period were 
analysed to find the mean values of each parameter. Quantitative losses were analysed as percentage of storage loss with respective to the stored quantity and presented descriptively.

\section{Results and Discussion}

\section{Stored Commodities}

Storing of remaining portion of the crop yield following consumption and/or selling was found out be quite common. As a storage commodity, unmilled rice dominated over other crops (Figs. 1-4). Unmilled rice was stored in all the DS divisions in Anuradhapura district. Both, Nadu and Samba rice variety types were found in stored lots. Maize was stored in five DS divisions (Galenbindunuwewa,

Horowpothana, Kahatagasdigiliya, Rambewa, and Vilachchiya) while greengram was found in stores in two DS divisions only (Rajanganaya and Rambewa).

\section{Storage Status of Commodities}

There was a substantial variation between the DS divisions in the proportion of unmilled rice stored following harvest. For rice variety type $N a d u$, percentage stored varied from $24.9 \%$ (in Padaviya) to $78.5 \%$ (in Mihintale) (Fig. 1). For rice variety type $S a m b a$, the percentage stroted varied from $13.9 \%$ (in Padaviya) to $71.5 \%$ (in Palagala) (Fig. 2). Contrasting to a previous study that reported storage of $30-50 \%$ of the total unmilled rice production by Sri Lankan farmers (Gunarathna and Karunaratne 2009), the percentage stored range was broader. However, in the present study, mean percentage of unmilled rice stored in Anuradhapura district was found to be lower than that previous study.

Compared with unmilled rice, the number of DS divisions stored greengram or maize after harvesting was relatively lower. Furthermore, the percentage stored with respective to the production was also lower in both maize and greengram compared to unmilled rice. In maize, percentage stored varied from $3.3 \%$ (in Vilachchiya) to $33.6 \%$ (in Rambewa) (Fig. 3). For Greengram, storage was 7\% in Rajanganaya and $52.5 \%$ in Rambewa (Fig. 4).

The percentage loss of paddy during the storage was relatively similar for two rice variety types irrespective of the DS divisions. For rice variety type $N a d u$, percentage storage losses ranged from 2.6\% (in Rambewa) to $8.23 \%$ (in Palagala) (Fig. 5). The rice variety type Samba, percentage storage losses ranged from $2.6 \%$ (in Galenbidunuwewa) to $13 \%$ (in Kekirawa) (Fig. 6). However, there were no significant differences between DS divisions for the percentage loss of given rice variety types (data not shown). This study revealed that on average, the storage loss of unmilled rice in Anuradhapura district is $5.4 \%$. This is closely in agreement with Palipane (2000), who recorded 4 - 6\% storage loss of unmilled rice in Sri Lanka. Qayyum (1974) recorded 2-10\% storage loss of unmilled rice in Pakistan. Furthermore, Palipane (2000) reported that among many factors that cause post-harvest losses, insects claim the major responsibility. Fernando et al. (1988) reported that insects cause up to $8.8 \%$ loss in unmilled storage. Future research is needed to investigate the contribution of these factors to the storage loss of grains. The percentage loss of maize did not exceed 5\% except in Rambewa, which recorded $13.3 \%$ loss at storage (Fig. 7). However, there were no significant differences between the losses in 4 DS divisions (data not 


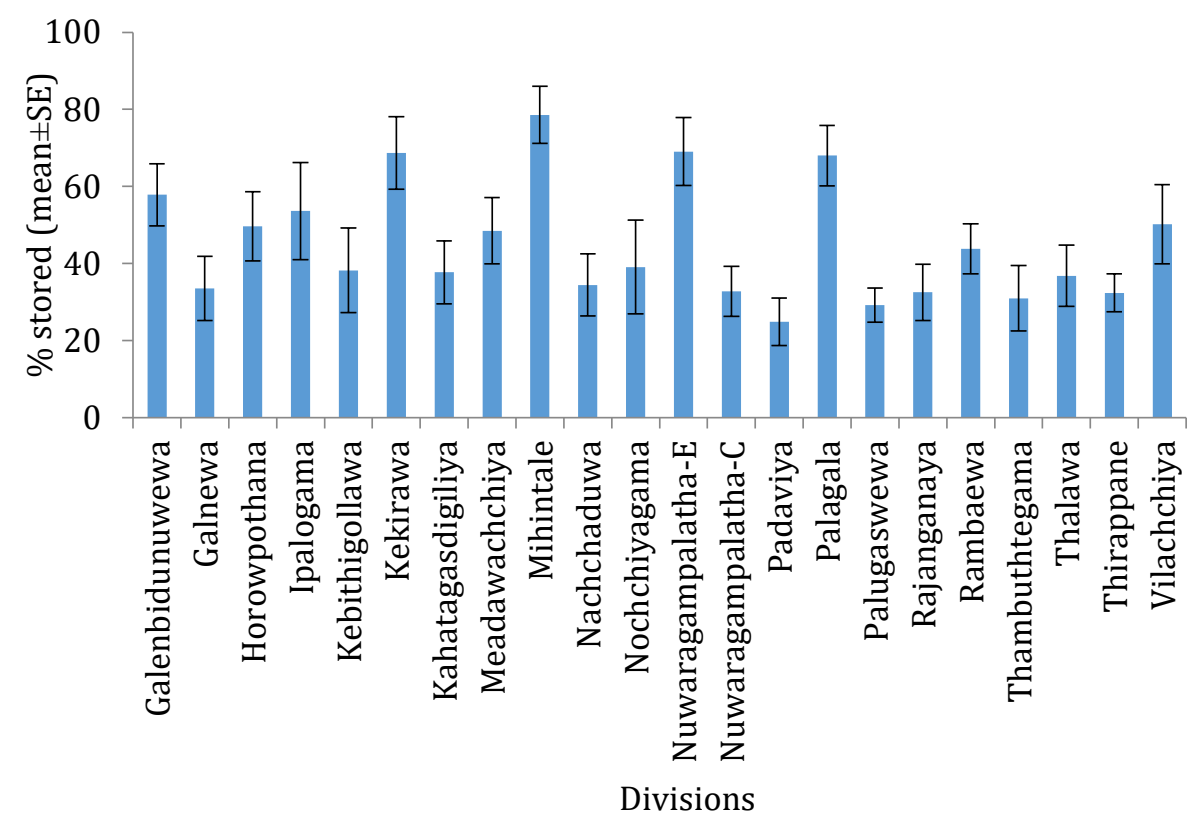

Figure 1. Percentage (mean \pm SE) of rice variety type Nadu (unmilled) stored following harvest in different DS divisions of Anuradhapura district.

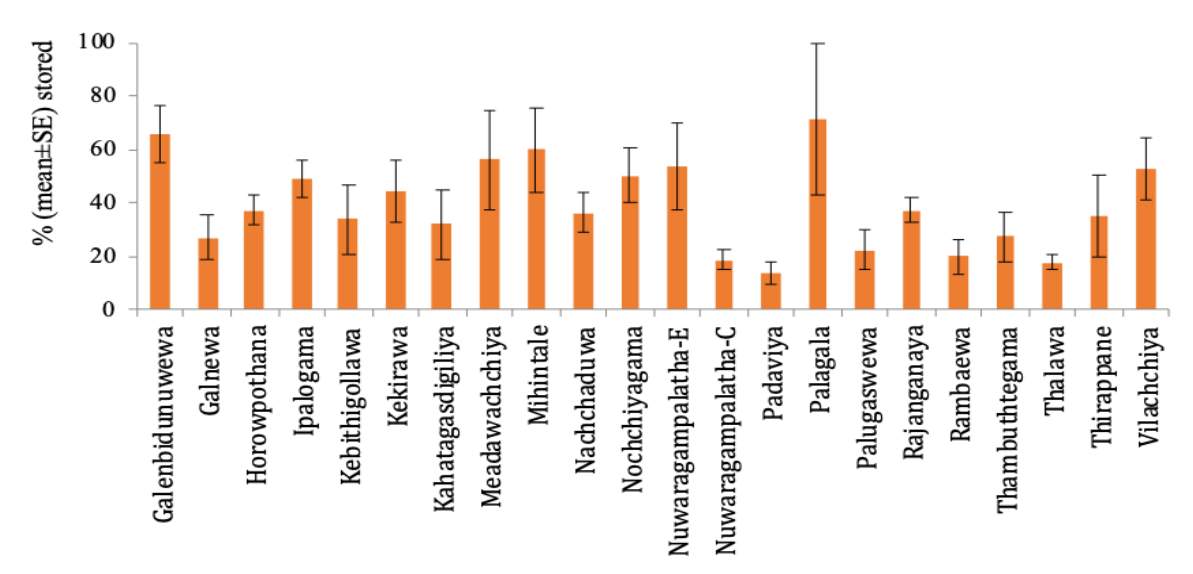

Divisions

Figure 2. Percentage (mean $\pm S E$ ) of rice variety type Samba (unmilled) stored following harvest in different DS divisions of Anuradhapura district.

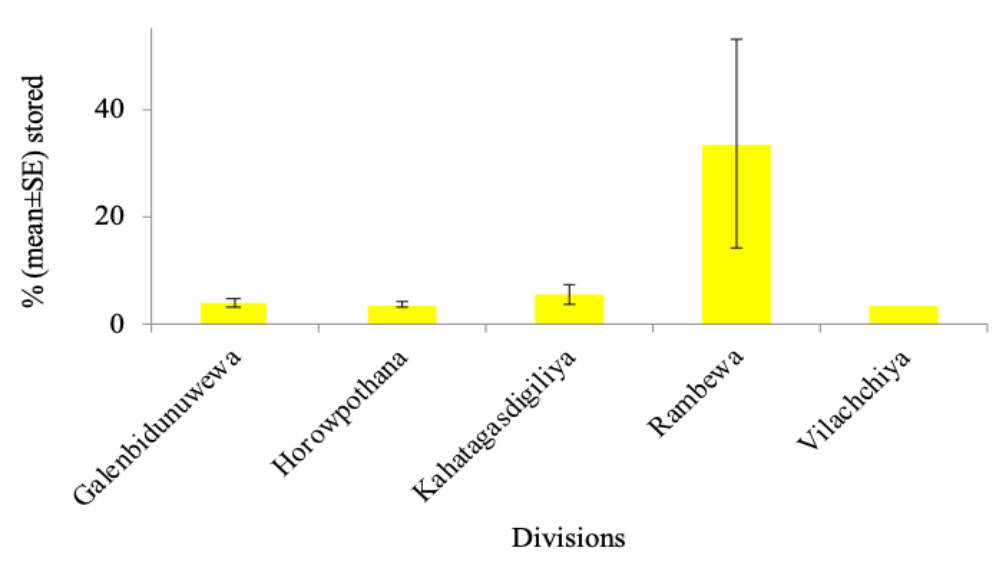

Figure 3. Percentage (mean \pm SE) of maize stored following harvest in different DS divisions of Anuradhapura district.

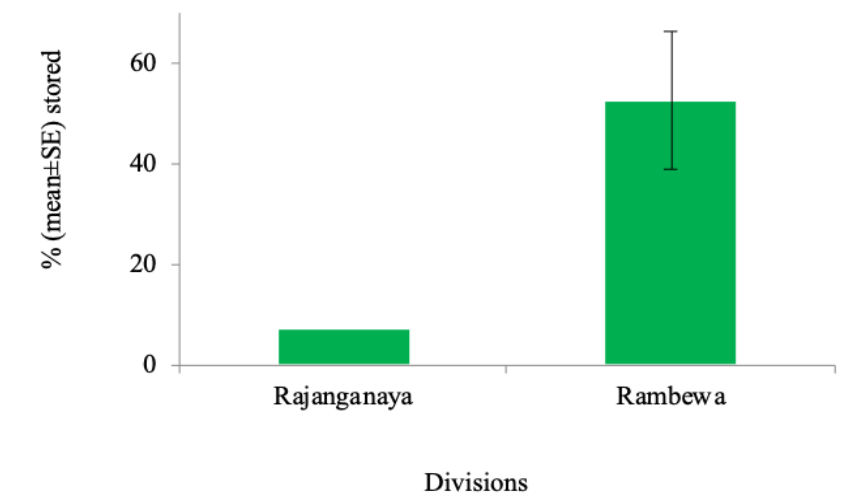

Figure 4. Percentage (mean \pm SE) of greengram stored following harvest in different DS divisions of Anuradhapura district. 


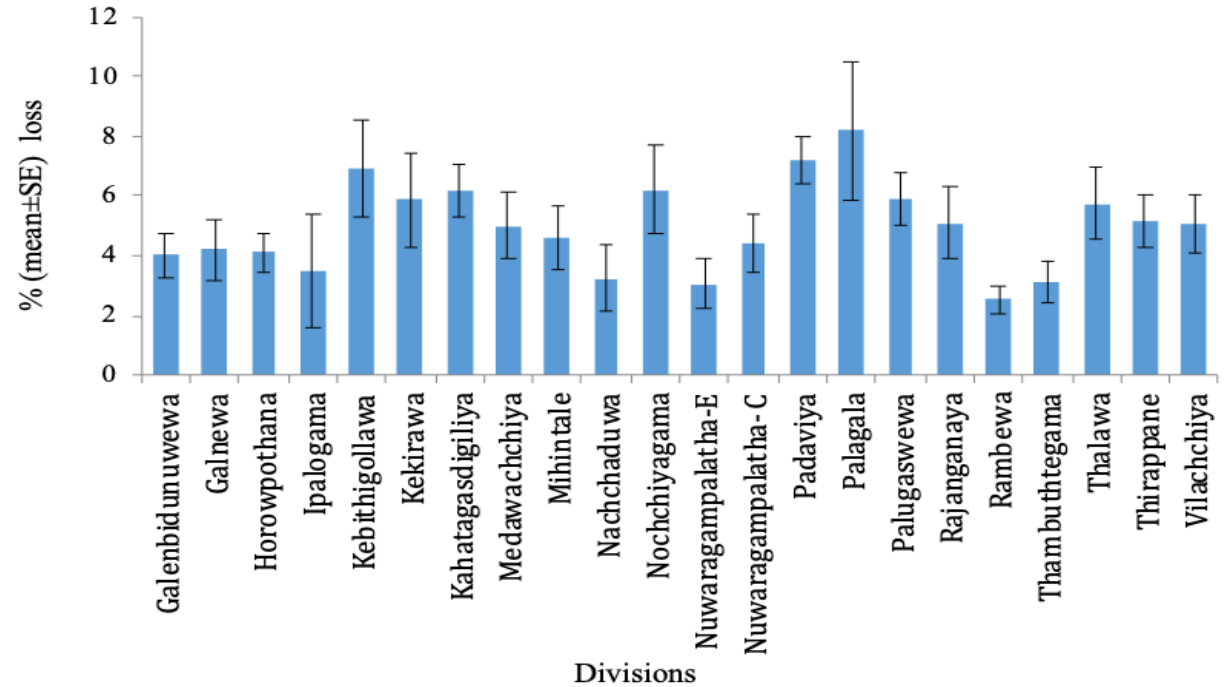

Figure 5. Percentage loss (mean \pm SE) of paddy (variety Nadu) during storage in different DS divisions of Anuradhapura district.

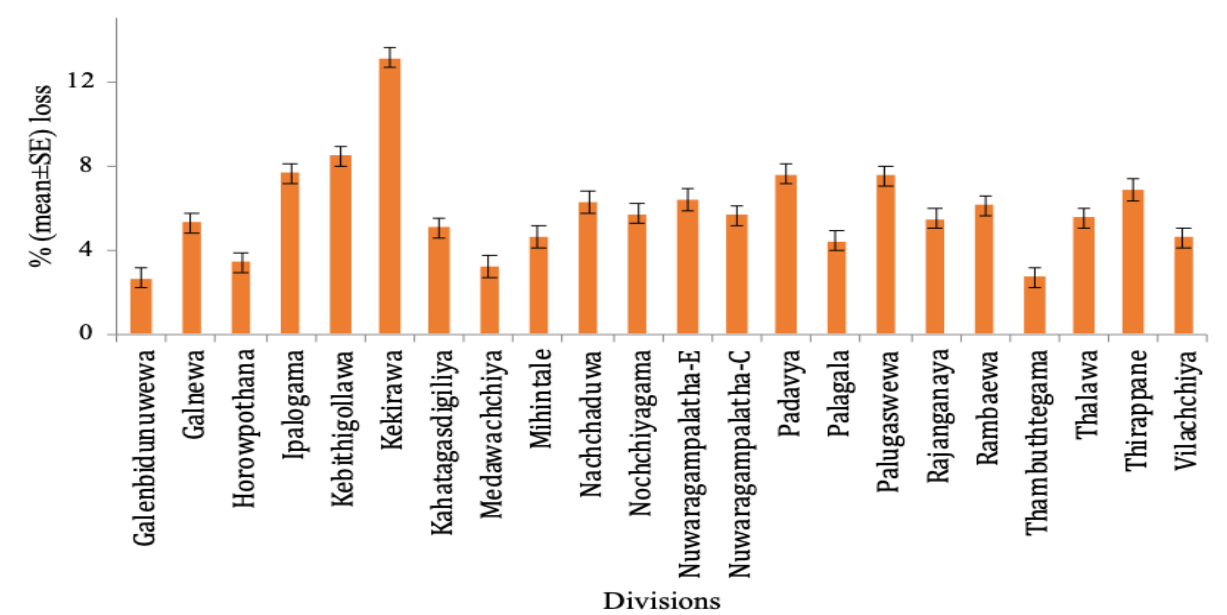

Figure 6. Percentage loss (mean \pm SE) of paddy (variety Samba) during storage in different DS divisions of Anuradhapura district.

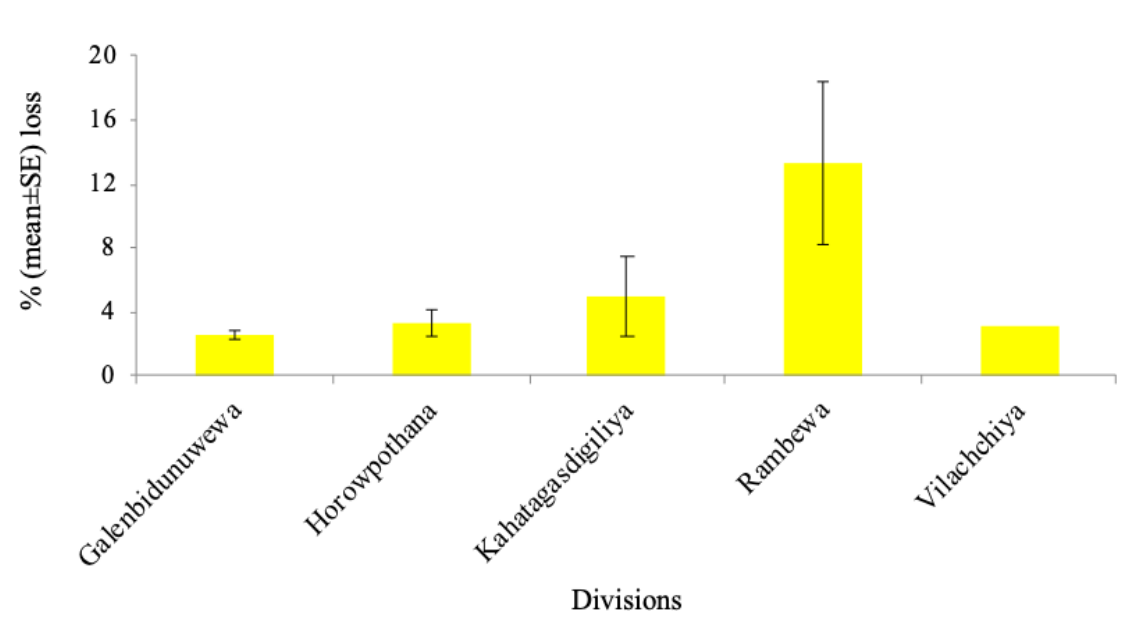

Figure 7. Percentage loss (mean \pm SE) of maize during storage in different DS divisions of Anuradhapura district.

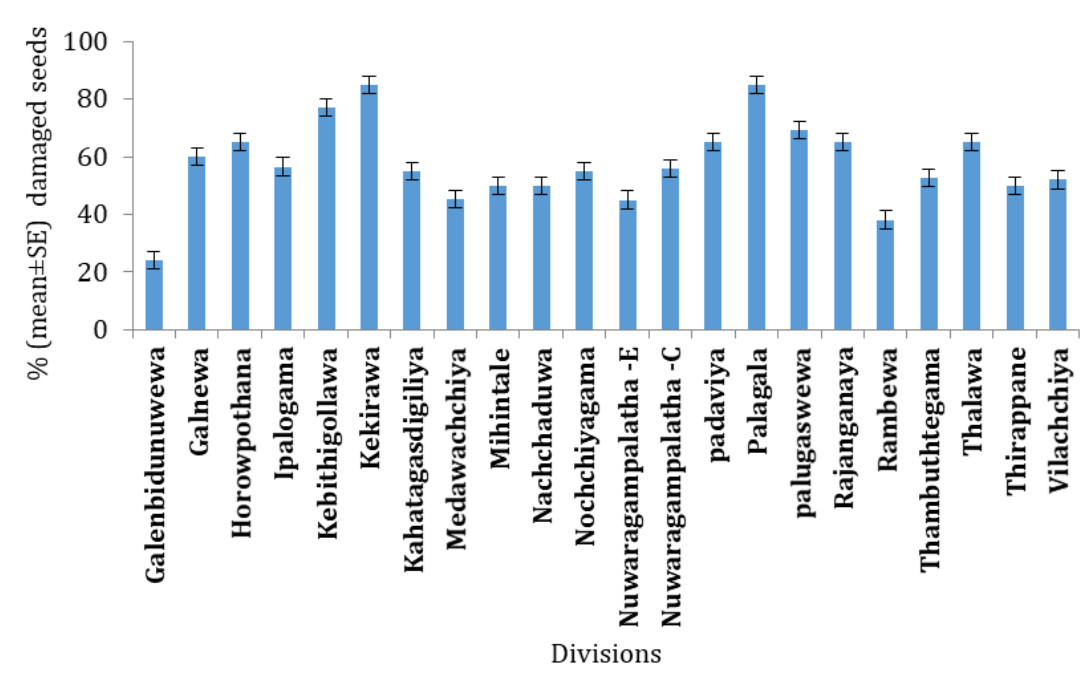

Figure 8. Percentage of famer families experienced damaged seeds in stored paddy. 


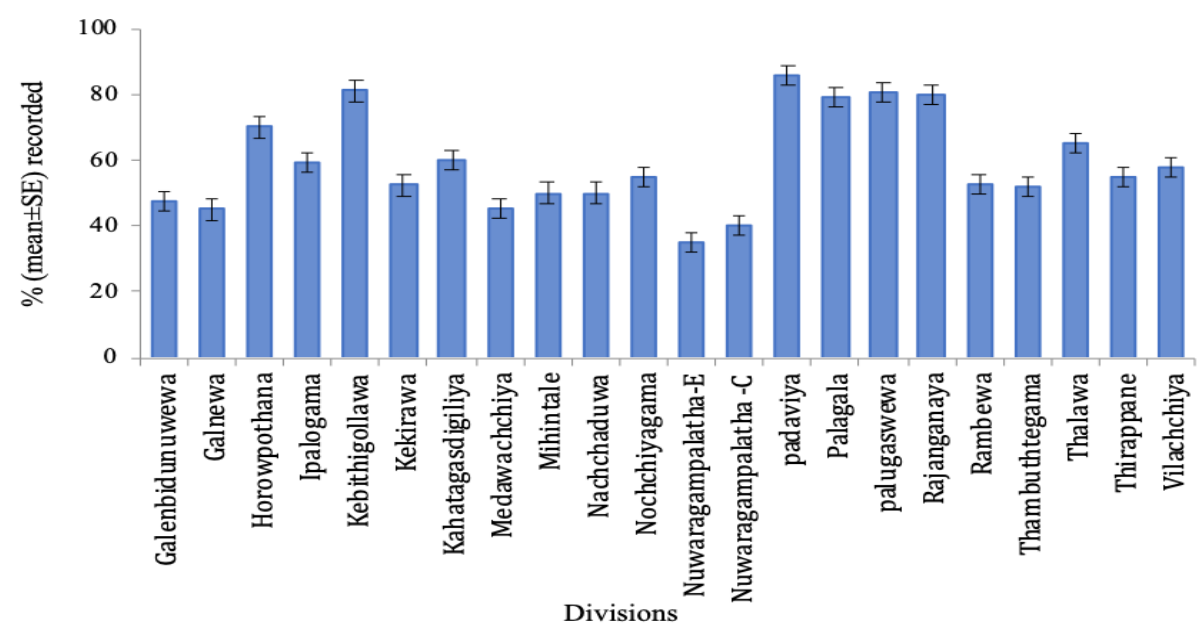

Figure 9. Percentages of farmer families experienced grain flour/dust in stored paddy

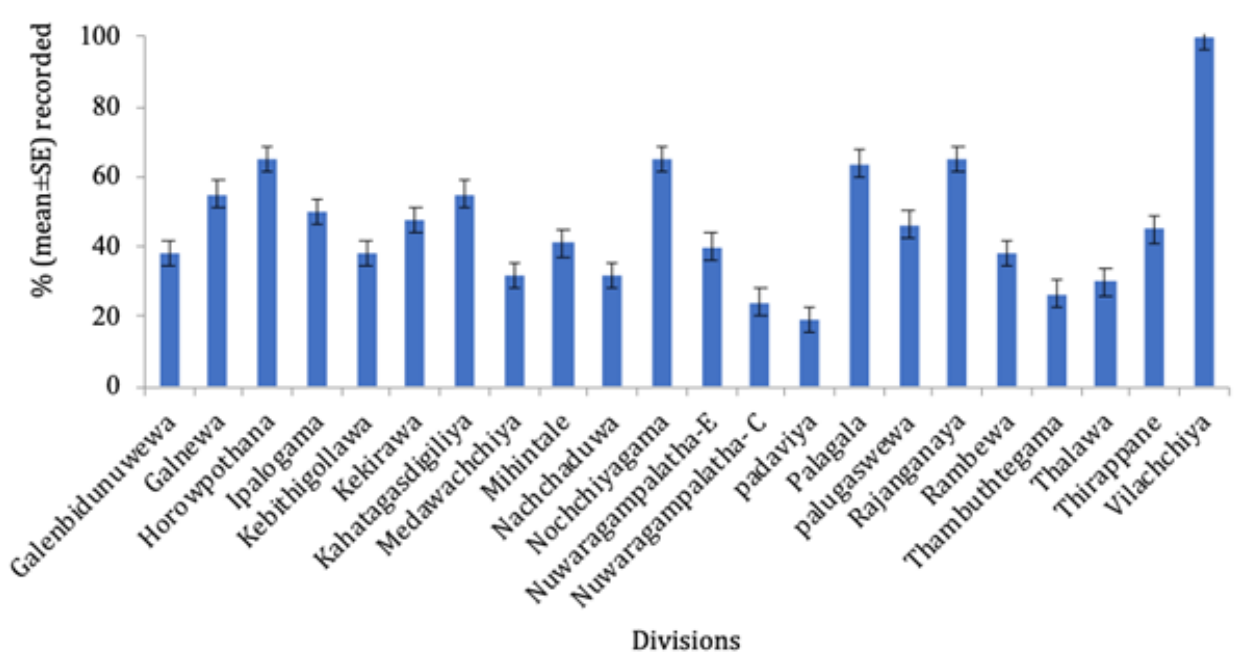

Figure 10. Percentage of farmer families experienced unfilled/empty seeds in stored paddy

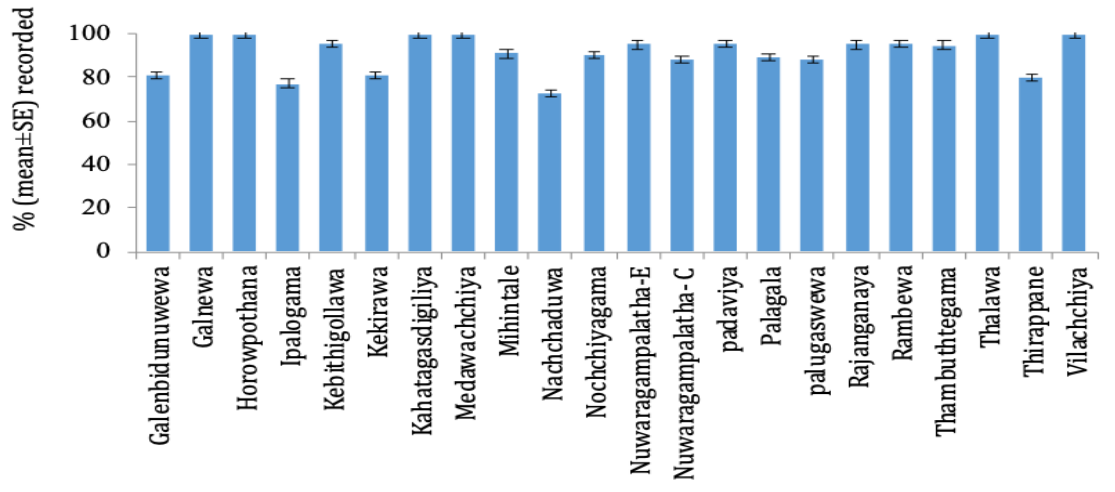

Divisions

Figure 11. Percentage of farm families experienced faecal matter in stored paddy

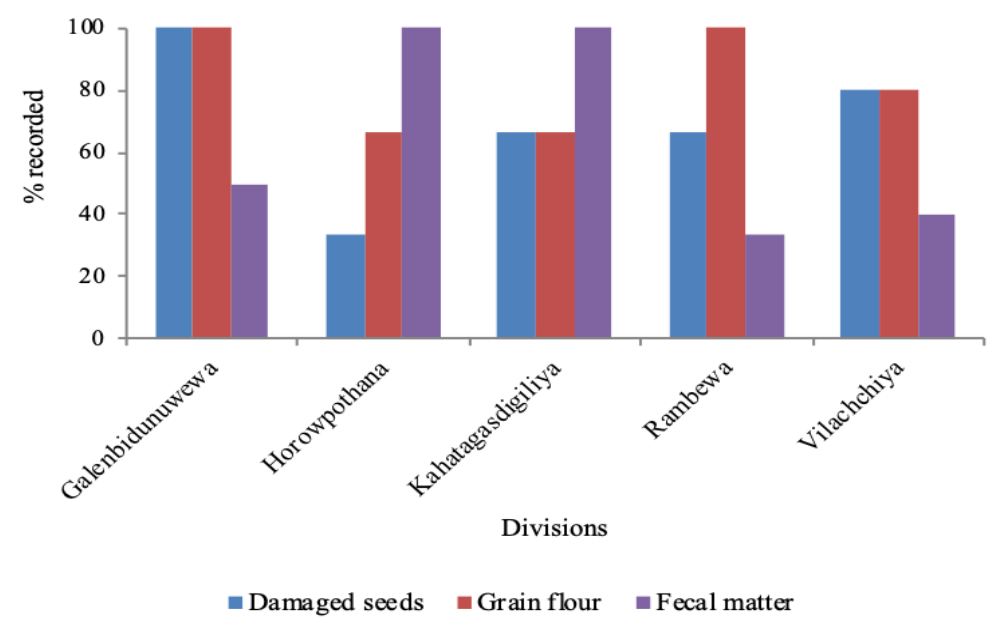

Figure 12. Percentage of farmer families experienced qualitative losses of stored maize 


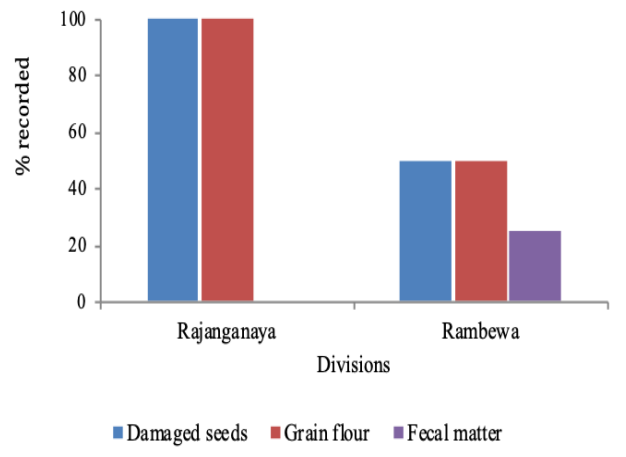

Figure 13. Percentage of farmer families experienced qualitative losses in stored greengram

not shown). This is comparable with Qayyum (1974) reported that drying and storage loss of maize in Pakistan is $2-10 \%$.

\section{Qualitative Losses of Stored Commodities}

Four types of qualitative losses were found in stored commodities. These were damaged seeds, grain flour, unfilled grains and presence of faecal matter. While the apparent cause for these conditions being the activities of insects, rodents and moulds, the future research should be designed to find the exact reason/s underlying. The highest percentage of damaged rice seeds was recorded in Kekirawa and Palagala (85\%) whereas the lowest percentage was recorded in Galenbindunuwewa (24\%) (Fig. 8). The highest and lowest percentages of grain flour/dust in stored rice were recorded in Padaviya (86\%) and Nuwaragampalatha East (35\%), respectively (Fig. 9). The highest empty grains percentage was recorded in Vilachchiya (100\%) whereas the lowest was recorded in Padaviya (19\%) (Fig. 10). At least, 75\% of rice stored in all the DS divisions were contaminated with faecal matter (Fig. 11).

Previous studies conducted in Sri Lanka have revealed that nearly $80 \%$ of the storage losses of grains are due to insect attack. These losses cause primarily loss of weight, nutrients and germinability, occurrence of bad smell and taste, changes of colour, clump of grains, and growth of fungus. These result in economic loss due to reduced market value (Wijayaratne and Rajapakse 2015).

In maize, the qualitative damage was substantial as the mean percentage loss is approximately $33 \%$. The percentages of damaged seeds and grain flour/dust were either equal or higher than $67 \%$ extending to $100 \%$ loss in certain DS divisions. Furthermore, $100 \%$ of farmer families experienced faecal matter in grains (Fig. 12) indicating the requirement of proper sanitation practices during post-harvest processing of durable commodities ensuring food safety.

Even though the qualitative losses of greengram were reported only in Rajanganaya and Rambewa, while the reported losses were exceeding the minimum of 50\%. Damaged seeds and grain flour/dust were the common form of losses (Fig. 13). The presence of faecal matter experienced by $25 \%$ of the families reiterate the importance of adopting hygienic practices in post-harvest operations.

\section{Conclusions}

The main durable crops stored following harvest by the farmers in Anuradhapura district include rice, maize and greengram. The percentage of crops stored varied with the crop and also across the DS divisions. Both quantitative and qualitative losses and differences in their percentage of losses were observed in different DS divisions. Future research should be designed to identify the causative factors for the 
losses occurred and the reasons for the differences between the DS divisions on the losses occurred in durable agricultural commodities during storage.

Conflicts of Interest: The authors have no conflicts of interest regarding this publication.

\section{References}

Dowell F E, Dowell C N (2017) Reducing grain storage losses in developing countries. Qual Assur Saf Crop 9:93-100.

Fernando M D, Palipane K B, Adikaranaike T B (1988) Improvement of farm level storage methods in Sri Lanka. Trop Post Harv Tech 1:4767.

Gunarathna T V N M, Karunaratne M S C (2009) Laboratory evaluation of some Sri Lankan plants as post-harvest grain protectants for the control of rice weevil Sitophilus oryzae. Vidyod J Sci 14:69-83.

Gustavson J, Cederberg C, Sonesson U, Van Otterdijk R, Meybeck A (2011) Global food losses and food waste extent, causes and prevention. Food and Agriculture Organization. Rome 38.

Hagstrum D W, Subramanyam, B (2006) Fundamentals of Stored-Product Entomology. AACC International. St Paul, 6-10.

Kader A (2002) Postharvest technology of horticultural crops. University of California, Agriculture and Natural Resources. Oakland. 535.

Palipane K B (2000) Milling and quality improvement in rice. Proceeding of rice symposium. Gannoruwa, Sri-Lanka, 14-15.
Proctor D L (1994) Grain storage techniquesEvaluation and trends in developing countries. Food and Agriculture Organization. Rome. Italy 224.

Qayyum H A (1974) Losses caused to stored products by insect pests in Pakistan and measures for their control. http://spiru.cgahr.ksu.edu/proj/iwcspp/pdf2/ 2/49.pdf. retrieved on: 11 January 2016.

Wijayaratne W (2020) Covid-19 and Postharvest food protection. Sunday Times. (http://www.sundaytimes.lk/article/1119068/ covid-10-and-post-harvest-food

protection).retrieved on: 08 May 2020.

Wijayaratne W, Rajapakse R (2015) Dilemma of stored paddy: Insect pest infestation. Daily News. http://www.Dailynews.lk. retrieved on: 12 January 2020.

Wijayaratne L K W, Fernando M D, Palipane K B (2009) Control of insect pests under ware-house conditions using smoke generated from partial combustion of rice (paddy) husk. J Natl Sci Foundation of Sri Lanka 37: 125-134.

Wijayaratne L K W, Arthur F H, Whyard S (2018) Methoprene and control of stored-product insects. J Stored Prod Res 76: 161-169.

Zorya S, Morgan N, Diaz Rios L, Hodges R, Bennett B, Stathers T, Mwebaze P, Lamb J (2011) Missing food-the case postharvest grain losses in Sub-Saharan Africa. World Bank, Washington D.C. 1-2. 